2 Research Square
Preprints are preliminary reports that have not undergone peer review.

They should not be considered conclusive, used to inform clinical practice, or referenced by the media as validated information.

\title{
The Clinical and Imaging Findings of Patent Ductus Venosus in Children: A Series of Nine Cases
}

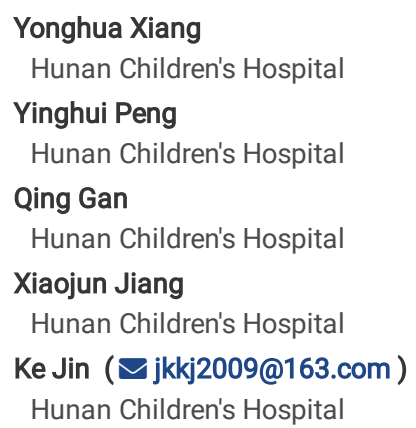

Research Article

Keywords: Patent ductus venosus, Portosystemic shunt, Congenital, Children, Imaging

Posted Date: December 16th, 2021

DOI: https://doi.org/10.21203/rs.3.rs-1152906/v1

License: @ (i) This work is licensed under a Creative Commons Attribution 4.0 International License. Read Full License 


\section{Abstract}

Purpose: To retrospectively analyze the clinical and imaging findings of patent ductus venosus (PDV), so as to improve the diagnostic accuracy of the disease and reduce missed diagnosis and misdiagnosis.

Methods Medical records of 9 patients with PDV were retrospectively reviewed. The clinical, and laboratory test data were extracted from the electronic medical records. Two radiologists and one sonographer reviewed all imaging examinations retrospectively.

Results 9 patients with PDV were reviewed, including 7 males and 2 females, aged from 16 days to 16.5 years. The initial clinical presentations of PDV were varied, but jaundice and respiratory symptoms were the most common. Laboratory tests showed that $5 / 9$ cases had hypoxemia, $2 / 9$ had hyperammonemia, 7/9 had hyperbilirubinemia, 6/9 had abnormal coagulation function, 4/9 had abnormal myocardial enzymes, 8/9 had hepatic dysfunction, and $3 / 9$ had renal dysfunction. The direct imaging sign of PDV was a vascular structure connecting the left branch of portal vein(LPV) to the inferior vena cava(IVC), running in the depth of the Arantius sulcus. The secondary imaging findings were as follows: All the patients had enlarged liver. 3 patients presented with hypoperfusion in right lobe of liver. The spleen was enlarged in 8 cases but shrank in one. Dilated LPV and atrophic right branch of portal vein (RPV) were observed in all patients. The main portal vein (MPV) was dilated in 8 cases and shrank in one. Dilated right heart and pulmonary artery were observed in all cases. Abnormal renal imaging was observed in 2 patients. The complications and coexistent malformations were as follows: Brain MRI indicated hepatic encephalopathy in 4 cases. 7/9 patients were combined with other malformations, and the most common coexistent malformations were congenital heart disease (CHD) and vascular abnormalities, with 5 and 6 cases respectively.

Conclusions PDV can lead to multi-system lesions. The clinical presentations and laboratory findings were diverse. The diagnosis of PDV depends on imaging examinations, and it is important to evaluate the secondary imaging changes. Complications and coexistent malformations were common, and we need to prevent omissions during the imaging evaluations.

\section{Introduction}

PDV was an extremely rare form of congenital portosystemic shunt and results in diversion of portal blood into the systemic circulation ${ }^{[1]}$. It entails a risk of life-threatening complications, which may be prevented or cured by their closure. Early detection of the shunt and proper management leads to a good prognosis and prevention of serious complications development. PDV can be diagnosed by noninvasive imaging studies including ultrasonography and computed tomography. However, due to the diversity of clinical symptoms and incomplete knowledge of this disease, the clinicians often failed to prescribe the targeted inspection request, resulting in missed diagnosis and misdiagnosis. Only a very few cases of PDV have been reported so far based on small case series, case reports, or literature reviews ${ }^{[2,3]}$. The clinical features, complications and radiological findings from portosystemic shunt have not been clarified. In this paper, we retrospectively analyzed the clinical presentations, laboratory test data and imaging findings of 9 patients with PDV, in order to improve a more comprehensive recognition of this disease. Our relatively larger cohort has allowed us to confirm broadly on previous observations and add some new findings.

\section{Materials And Methods}

\section{Patients}

Nine patients with PDV were identified in Hunan Children's Hospital from May 2013 to December 2020, including 7 males and 2 females, aged from 16 days to 16.5 years with a median age of 1.6 years. PDV was confirmed by computed tomography and ultrasound. We defined PDV according to the criteria by Blanc et al. ${ }^{[4]}$ : intrahepatic shunt running in the depth of the Arantius sulcus, between left and caudate lobes from the proximal part of the left branch of portal vein to the terminal part of the left hepatic vein. Patient demographic information, clinical symptoms, laboratory tests were obtained from the electronic medical records. This retrospective study was approved by the institutional review board of our hospital, and the requirement for informed consent was waived.

\section{Examinations}

All the patients underwent abdominal contrast-enhanced computed tomography (CT) and ultrasound examinations. All the patients underwent ultrasound and/or CTA of the cardiovascular system. Brain MRI was performed in 7 patients to evaluate hepatic encephalopathy. Abdominal imaging findings were based on CT. Observations of the heart and coexistent malformations were based on CT and ultrasound. Pulmonary arterial pressures were measured by ultrasound. Two radiologists and one sonographer, with over 15 years of experience in imaging of the cardiovascular system reviewed all imaging examinations retrospectively. When the diagnosis is inconsistent, we reach a consensus through consultation.

\section{Results}

The clinical characteristics and laboratory tests of 9 patients were summarized in Table 1. PDV diameter ranged from $4.0 \mathrm{~mm}$ to $17.5 \mathrm{~mm}$. The initial clinical presentations of PDV were varied, but jaundice and respiratory symptoms were the most common. Laboratory tests showed that $5 / 9$ cases had hypoxemia, 2/9 had hyperammonemia, 7/9 had hyperbilirubinemia, 6/9 had abnormal coagulation function, 4/9 had abnormal myocardial enzymes, $8 / 9$ had hepatic dysfunction, and $3 / 9$ had renal dysfunction. The imaging findings and coexistent malformations of 9 patients were summarized in Table 2 . The direct imaging sign of PDV was a vascular structure connecting the left branch of portal vein(LPV) to the inferior vena cava(IVC), running in the depth of the Arantius sulcus(Fig. 1). The secondary imaging findings of PDV were as follows: All the patients had enlarged livers, especially the left lobe, and one of the patients presented with diffuse nodules in the liver(Fig. 2). 3 patients presented with hypoperfusion in right lobe of liver at the abdominal contrast-enhanced CT. The spleen was enlarged in 8 cases but shrank in one. Dilated LPV and atrophic right branch of portal vein (RPV) were observed in all patients. The main portal 
vein (MPV) was dilated in 8 cases and shrank in one. Dilated right heart and pulmonary artery were observed in all cases. Abnormal renal imaging was observed in 2 patients. The complications and coexistent malformations were as follows: Brain MRI indicated hepatic encephalopathy in 4 cases(Fig. 3 ). $7 / 9$ patients were combined with other malformations, including CHD, vascular abnormalities, genital deformity and schizencephaly. The most common coexistent malformations were CHD and vascular abnormalities, with 5 and 6 cases respectively. The most common types of CHD associated with PDV were ASD and PDA.

Table 1

the clinical characteristics and laboratory tests of nine patients

\begin{tabular}{|c|c|c|c|c|c|c|c|c|c|c|c|}
\hline Case & Sex & $\begin{array}{l}\text { Age } \\
\text { at } \\
\text { diagnosis }\end{array}$ & $\begin{array}{l}\text { Diameter } \\
\text { of PDV }\end{array}$ & Symptoms & Hypoxemia & $\begin{array}{l}\text { Blood } \\
\text { ammonia } \\
\text { (NH4) }\end{array}$ & Hyperbilirubinemia & $\begin{array}{l}\text { Coagulation } \\
\text { function }\end{array}$ & $\begin{array}{l}\text { Myocardial } \\
\text { enzyme }\end{array}$ & $\begin{array}{l}\text { Hepatic } \\
\text { dysfunction }\end{array}$ & $\begin{array}{l}\text { Reni } \\
\text { dysf }\end{array}$ \\
\hline 1 & $\mathrm{~F}$ & $16 d$ & $7.0 \mathrm{~mm}$ & $\begin{array}{l}\text { Icterus and } \\
\text { cough }\end{array}$ & yes & normal & yes & Abnormal & Abnormal & yes & yes \\
\hline 2 & M & $18 d$ & $5.0 \mathrm{~mm}$ & Cyanosis & yes & normal & yes & Abnormal & normal & yes & yes \\
\hline 3 & M & $25 d$ & $4.5 \mathrm{~mm}$ & Icterus & yes & elevated & yes & Abnormal & normal & yes & norn \\
\hline 4 & M & $30 d$ & $7.1 \mathrm{~mm}$ & Icterus & normal & elevated & yes & normal & normal & yes & norn \\
\hline 5 & $\mathrm{~F}$ & $1.6 y$ & $9.5 \mathrm{~mm}$ & $\begin{array}{l}\text { Cough and } \\
\text { fever }\end{array}$ & yes & normal & yes & normal & Abnormal & yes & norn \\
\hline 6 & $M$ & $4.2 y$ & $4.0 \mathrm{~mm}$ & $\begin{array}{l}\text { Cough and } \\
\text { wheeze } \\
\text { repeated }\end{array}$ & normal & normal & normal & normal & normal & yes & norn \\
\hline 7 & M & $4.9 y$ & $10.0 \mathrm{~mm}$ & $\begin{array}{l}\text { Frequent } \\
\text { pneumonia }\end{array}$ & yes & normal & yes & Abnormal & Abnormal & yes & yes \\
\hline 8 & $M$ & $10.2 y$ & $17.5 \mathrm{~mm}$ & $\begin{array}{l}\text { Frequent } \\
\text { pneumonia } \\
\text { and } \\
\text { hemoptysis }\end{array}$ & normal & normal & normal & Abnormal & normal & normal & norn \\
\hline 9 & $M$ & $16.5 y$ & $14.5 \mathrm{~mm}$ & $\begin{array}{l}\text { Yellowing } \\
\text { sclera and } \\
\text { skin for } \\
\text { two years }\end{array}$ & normal & normal & yes & Abnormal & Abnormal & yes & norn \\
\hline
\end{tabular}

F female, M male, d day, y year 
Table 2

the imaging findings and coexistent malformations of nine patients

\begin{tabular}{|c|c|c|c|c|c|c|c|c|}
\hline Case & Liver/Spleen & $\begin{array}{l}\text { Liver } \\
\text { perfusion }\end{array}$ & Portal vein (PV) & $\begin{array}{l}\text { Heart } \\
\text { dilation }\end{array}$ & $\begin{array}{l}\mathrm{PH} \\
(\mathrm{mmHg})\end{array}$ & $\begin{array}{l}\text { Renal } \\
\text { imaging }\end{array}$ & Brain & Coexistent malformations \\
\hline 1 & $\begin{array}{l}\text { Enlarged/ } \\
\text { small;CE } \\
\text { reduced }\end{array}$ & $\begin{array}{l}\text { Hypoperfusion } \\
\text { in right lobe }\end{array}$ & $\begin{array}{l}\text { MPV and RPV } \\
\text { small;LPV and UV } \\
\text { cystic dilated }\end{array}$ & $\begin{array}{l}\text { Right } \\
\text { heart }\end{array}$ & Yes/32 & $\begin{array}{l}\text { CE of } \\
\text { kidneys } \\
\text { is } \\
\text { reduced }\end{array}$ & NA & $\begin{array}{l}\text { ASD;PDA;Multiple } \\
\text { arteriovenous fistulas }\end{array}$ \\
\hline 2 & Enlarged & Normal & $\begin{array}{l}\text { MPV and LPV } \\
\text { dilated;thrombus in } \\
\text { LPV;RPV small }\end{array}$ & $\begin{array}{l}\text { Right } \\
\text { heart }\end{array}$ & Yes/38 & $\begin{array}{l}\text { Diffuse } \\
\text { lesion of } \\
\text { kidneys }\end{array}$ & $\begin{array}{l}\text { Neonatal } \\
\text { encephalopathy }\end{array}$ & $\begin{array}{l}\text { ASD;PDA;VSD; } \\
\text { External genital deformity }\end{array}$ \\
\hline 3 & $\begin{array}{l}\text { Diffuse } \\
\text { nodules/ } \\
\text { enlarged }\end{array}$ & $\begin{array}{l}\text { Hypoperfusion } \\
\text { in right lobe }\end{array}$ & $\begin{array}{l}\text { MPV and LPV } \\
\text { dilated;RPV small }\end{array}$ & $\begin{array}{l}\text { Right } \\
\text { heart }\end{array}$ & Yes/28 & Normal & $\begin{array}{l}\text { Neonatal } \\
\text { encephalopathy }\end{array}$ & Hepatic arteriovenous fistula \\
\hline 4 & $\begin{array}{l}\text { Left lobe } \\
\text { enlarged/ } \\
\text { enlarged }\end{array}$ & Normal & $\begin{array}{l}\text { MPV and LPV } \\
\text { dilated;RPV small }\end{array}$ & $\begin{array}{l}\text { Right } \\
\text { heart }\end{array}$ & Yes/42 & Normal & $\begin{array}{l}\text { Suppurative } \\
\text { meningitis }\end{array}$ & $\begin{array}{l}\text { ASD;PDA; Abernethy } \\
\text { malformation }\end{array}$ \\
\hline 5 & $\begin{array}{l}\text { Left lobe } \\
\text { enlarged/ } \\
\text { enlarged }\end{array}$ & Normal & $\begin{array}{l}\text { MPV and LPV } \\
\text { dilated;RPV small }\end{array}$ & $\begin{array}{l}\text { Right } \\
\text { heart }\end{array}$ & Yes/25 & Normal & $\begin{array}{l}\text { Hepatic } \\
\text { encephalopathy }\end{array}$ & $\begin{array}{l}\text { ASD;PDA; } \\
\text { Skin multiple hemangioma }\end{array}$ \\
\hline 6 & Enlarged & Normal & $\begin{array}{l}\text { MPV and LPV } \\
\text { dilated;RPV small }\end{array}$ & $\begin{array}{l}\text { Right } \\
\text { heart }\end{array}$ & Yes/28 & Normal & NA & Congenital hypospadias \\
\hline 7 & Enlarged & $\begin{array}{l}\text { Hypoperfusion } \\
\text { in right lobe }\end{array}$ & $\begin{array}{l}\text { MPV and LPV } \\
\text { slightly dilated; RPV } \\
\text { small }\end{array}$ & $\begin{array}{l}\text { Right } \\
\text { heart }\end{array}$ & Yes/50 & Normal & $\begin{array}{l}\text { Hepatic } \\
\text { encephalopathy }\end{array}$ & No \\
\hline 8 & $\begin{array}{l}\text { Left lobe } \\
\text { enlarged/ } \\
\text { enlarged }\end{array}$ & Normal & $\begin{array}{l}\text { MPV dilated;LPV } \\
\text { cystic dilated;RPV } \\
\text { small }\end{array}$ & $\begin{array}{l}\text { Whole } \\
\text { heart }\end{array}$ & Yes/33 & Normal & $\begin{array}{l}\text { Hepatic } \\
\text { encephalopathy }\end{array}$ & $\begin{array}{l}\text { ASD;Schizencephaly;Bronchial } \\
\text { artery-pulmonary fistula; }\end{array}$ \\
\hline 9 & Enlarged & Normal & $\begin{array}{l}\text { MPV dilated;LPV } \\
\text { cystic dilated;RPV } \\
\text { small }\end{array}$ & $\begin{array}{l}\text { Right } \\
\text { heart }\end{array}$ & Yes/41 & Normal & $\begin{array}{l}\text { Hepatic } \\
\text { encephalopathy }\end{array}$ & No \\
\hline
\end{tabular}

\section{Discussion}

The ductus venosus (DV) is an embryonic vascular structure. In utero, DV connects the umbilical vein to IVC, allowing a portion of the oxygenated umbilical vein blood to bypass the liver and return to the heart, and spontaneous closure begins immediately after birth and complete functional closure usually occurs by about 18 days of age ${ }^{[5,6]}$. However, closure of DV may not happen after birth because of poorly developed intrahepatic portal system and lead to $\mathrm{PDV}^{[7]}$. PDV is more common in boys ${ }^{[3,8]}$, with a male to female ratio of $7: 2$ in this study. PDV was classified as a type of intrahepatic portosystemic shunt (PSS). PSS leads to portal venous blood bypassing the liver and directly entering the systemic circulation, resulting in decreased hepatic blood flow, increasing blood volume and toxic substances in the systemic circulation.

\section{Clinical symptoms and laboratory tests}

The clinical presentations of PDV were highly diverse ${ }^{[9-12]}$. In this study, the initial symptoms and signs were varied, but jaundice and respiratory symptoms were the most common. In the younger patients, jaundice was often the initial presentation, while in the older patients, repeated pulmonary inflammation was more common. Previous reports suggest PDV is a very rare cause of cholestatic jaundice ${ }^{[8]}$. Symptoms of patients with PDV can appear at different ages, which can be severe in infancy or initially asymptomatic and develop slowly with age.

Hepatic dysfunction secondary to PDV has been reported previously ${ }^{[13,14]}$. This study showed that $89 \%(8 / 9)$ of the cases had hepatic dysfunction. Hepatic dysfunction was an important initial presentation of PDV and may be secondary to reduction of blood flow in portal vein which deprives hepatocytes of nutrients and cause hepatic dysfunction including protein synthesis ${ }^{[14]}$. Hyperammonemia can be caused by hepatocellular insufficiency or abnormal shunting of portal blood from the intestine directly into the systemic circulation ${ }^{[15]}$, and hepatic encephalopathy occurred with hyperammonemia. The incidence of hyperammonemia in patients with PDV has been reported to be high. In a study involving 8 patients with PDV, the incidence of hyperammonemia was $100 \%{ }^{[16]}$. Hyperammonemia was detected in only $2(22 \%)$ cases in this study, and the serum ammonia concentrations of 4 cases with hepatic encephalopathy were within the normal range. Hypoxemia, hyperbilirubinemia and coagulation dysfunction associated with PDV have been reported previously ${ }^{[3,8,16]}$. In this study, the incidence of hypoxemia was $56 \%$, hyperbilirubinemia was $78 \%$, and coagulation dysfunction was $67 \%$. Few reports of myocardial enzyme abnormalities and renal dysfunction secondary to PDV have been reported. In this study, significant abnormalities in myocardial enzymes were detected in $4(44 \%)$ cases. All of these 4 cases had a relatively larger PDV diameter(7.0mm-14.5mm), we believed that PDV significantly increased the blood volume returning to heart, increased the ventricular load and led to myocardial damage. Renal dysfunction was detected in case 1 , case 2 and case7. The imaging findings of case 1 and case 2 were abnormal, while case7 were normal. Contrast-enhanced CT showed the MPV, splenic vein and superior 
mesenteric vein were small and renal enhancement was significantly reduced in case 1 . Therefore, we suggested that renal dysfunction may be secondary to PDV.

\section{Imaging findings}

Imaging examinations can make an accurate diagnosis based on the specific anatomic position of PDV. The direct imaging sign of PDV was a vascular structure from the anterior inferior to the posterior connecting LPV to IVC, running in the depth of the Arantius sulcus. PDV can be mistaken for hepatic veins if PDV diameter was close to that of hepatic veins on CT images, however, PDV communicates with LPV and in the early stage of portal vein, its density was higher than that of hepatic vein, which can be distinguished. It is important to evaluate the secondary imaging changes caused by PDV. PDV can lead to an increase of blood volume returning to right heart and then into the pulmonary artery, causing dilation of the right heart and pulmonary artery. All our cases had dilatation of right atrium, right ventricle and pulmonary artery. These signs were not specific for the diagnosis of PDV, but may be the first to be detected, since the initial presentation of patients with PDV were often respiratory symptoms and the chest imaging examination is performed first. In fact, in several cases of this study, the dilatation of pulmonary artery was first observed, followed by further examinations to confirm PDV. Case7 was admitted for several times for cough, and chest CT revealed obvious dilatation of right heart and pulmonary artery for unknown reasons, but abdominal examination was not performed during the previous examinations, leading to missed diagnosis for many times. So PDV should be considered as a possible cause in the presence of unexplained dilatation of right heart and pulmonary artery. PDV was previously reported to coexist with hypoplasia of the intrahepatic portal venous system $^{[3,13]}$. Dilated LPV and atrophic RPV were shown in all cases in this study. We speculated that PDV increased the blood flow of LPV, while decreased of RPV, leading to the dilatation of LPV and the dysplasia of RPV. This sign was rare observed in other types of portosystemic shunt, and it was a relatively characteristic indirect manifestation of PDV, which was of great value in suggesting PDV. Dysplasia of RPV may result in decreased blood flow to the right lobe of the liver, as manifested by decreased perfusion on CTA images. Hypoperfusion in the right lobe of the liver was observed in 3 cases at the portal phase in this study. In addition, enlargement of the liver and spleen was common, and the enlargement of the liver may be manifested as whole liver or left lobe.

\section{Complications and coexistent malformations}

Complications of portosystemic shunt depends on shunt ratio and on aging. When the shunt ratio is small, there may be asymptomatic, while the shunt ratio is large, it can lead to multiple systemic symptoms, such as pulmonary hypertension, hepatopulmonary syndrome, high-discharge heart failure,

gastrointestinal bleeding, membranous proliferative glomerulonephritis, and hepatic encephalopathy ${ }^{[9,17,18]}$. Hepatic encephalopathy due to cerebral effects of circulating toxins, which normally undergo first pass metabolism in the liver, is a critical problem in patients with PDV. The age of onset of encephalopathy is variable and partially related to the volume and duration of the shunt. In the previous reports ${ }^{[19]}$, when the shunt ratio is less than $30 \%$, symptoms associated with portosystemic shunt may not develop throughout the lifetime of the individual. When the shunt ratio exceeds $30 \%$, hepatic encephalopathy could develop at any time. When the shunt ratio exceeds $60 \%$, the risk of hepatic encephalopathy is increased. In this study, 4 cases were confirmed with hepatic encephalopathy by brain MRI. Unfortunately, the shunt ratio was not measured, but we found that the diameter of PDV was larger in these 4 cases, with the smallest diameter of $9.5 \mathrm{~mm}$, at the same time, the 4 cases were older, with the minimum age being 1.6 years. It is important to note that although hepatic encephalopathy is present, there may be no neurological symptoms or mild symptoms. 2 patients in this study had no neurological symptoms, although brain MRI suggested hepatic encephalopathy. Therefore, when the diameter of PDV is larger and the patients are older, regardless of whether they have neurological symptoms, we suggested that brain MRI should be performed to detect hepatic encephalopathy. In order to prevent these complications, shunts should be closed using endovascular or surgical methods, although spontaneous closure of portosystemic shunt including PDV may be expected to occur after 1-2 years $^{[20]}$.

Patients with PDV may be accompanied by other deformities ${ }^{[21]}$. In this study, $78 \%(7 / 9)$ of the cases were combined with other malformations involved multiple systems, including congenital heart disease (CHD), vascular abnormalities, genital deformity and schizencephaly. The most common coexistent malformations were $\mathrm{CHD}$ and vascular abnormalities, with 5 and 6 cases respectively in this study. Of the 5 cases combined CHD, 4 cases were from the younger age group(16d-1.6y).The most common types of CHD associated with PDV were ASD and PDA. There is a recognized association between extrahepatic shunts and CHD ${ }^{[22]}$. We believed that PDV is also associated with CHD. A review of the literatures showed that up to $25 \%$ of patients with PDV had $\mathrm{CHD}^{[21]}$. All of the cases in this study had dilation of the right atrium and right ventricle, so we speculated that PDV increased the blood volume returning to right heart, increased the pressure of right heart and pulmonary artery, thereby delayed or impeded the closure of ASD and PDA.

\section{Conclusion}

In conclusion, PDV was a rare vascular malformation that can lead to multi-system lesions. The clinical symptoms, signs and laboratory findings were diverse. The diagnosis of PDV mainly depends on imaging examinations, and it is important to evaluate the secondary imaging changes. Complications and coexistent malformations were common, so we need to prevent omissions during the imaging evaluations.

\section{Abbreviations}

ASD atrial septal defect, CHD congenital heart disease,CT computed tomography, DV ductus venosus, IVC inferior vena cava, LPV the left branch of portal vein, MPV the main portal vein, PDA patent ductus arteriosus, PDV patent ductus venosus, PH pulmonary hypertension, PSS portosystemic shunt, PV portal vein, RPV the right branch of portal vein, UV umbilical vein, VSD ventricular septal defect.

\section{Declarations}


This retrospective study was approved by the institutional review board of our hospital, and the requirement for informed consent was waived.

Consent for publication $\square$ Not applicable.

Availability of data and material: The datasets used and/or analyzed during the current study are available from the corresponding author on reasonable request.

Competing interests: The authors have no conflict of interest to declare.

Funding: This study was supported by the science and technology innovation Program of Hunan Province, Grant/Award Numbers: 2020 SK50516.

\section{Authors' contributions:}

Ke Jin: Conceived and designed the experiments. Yonghua Xiang: Analyzed the data and wrote the paper. Yinghui Peng, Qing Gan and Xiaojun Jiang: Collected and analyzed the data. All authors have read and approved the manuscript.

Acknowledgements: Not applicable

\section{References}

1. De Vito C, Tyraskis A, Davenport M et al (2019) Histopathology of livers in patients with congenital portosystemic shunts (Abernethy malformation): a case series of 22 patients. Virchows Arch 474:47-57

2. Ikeda S, Yamaguchi Y, Sera Y et al (1999) Surgical correction of patent ductus venosus in three brothers. Dig Dis Sci 44:582-589

3. Yoshimoto Y, Shimizu R, Saeki T et al (2004) Patent ductus venosus in children: a case report and review of the literature. J Pediatr Surg 39:E1-E5

4. Blanc T, Guerin F, Franchi-Abella S et al (2014) Congenital portosystemic shunts in children: a new anatomical classification correlated with surgical strategy. Ann Surg 260:188-198

5. Kondo M, Itoh S, Kunikata T et al (2001) Time of closure of ductus venosus in term and preterm neonates. Arch Dis Child Fetal Neonatal Ed 85:F57-59

6. Fugelseth D, Lindemann R, Liestol K et al (1997) Ultrasonographic study of ductus venosus in healthy neonates. Arch Dis Child Fetal Neonatal Ed 77:F131-F134

7. Ikeda S, Yamaguchi Y, Sera Y et al (1999) Surgical correction of patent ductus venosus in three brothers. Dig Dis Sci 44:582-589

8. Kamali L, Moradi M, Ebrahimian S et al (2019) Patent ductus venosus in an infant with direct hyperbilirubinemia. Clin Case Rep 7:1430-1434

9. Konstas AA, Digumarthy SR, Avery LL (2011) et a1. Congenital portosystemic shunts: imaging findings and clinical presentations in 11 patients. Eur J Radiol 80:175-181

10. Torigoe M, Maeshima K, Takeshita Y (2013) Congenital intrahepatic portosystemic venous shunt presenting with paraparesis as the initial symptom. Intern Med 52:2439-2442

11. Ohno T, Muneuchi J, Ihara K (2008) et a1. Pulmonary hypertension in patients with congenital portosystemic venous shunt: a previously unrecognized association, vol 121. Pediatrics, pp e892-899

12. Lautz TB, Shah SA, Superina RA (2016) Hepatoblastoma in children with congenital portosystemic shunts. J Pediatr Gastroenterol Nutr 62:542-545

13. Jacob S, Farr G, De Vun D et al (1999) Hepatic manifestations of familial patent ductus venosus in adults. Gut 45:442-445

14. Uchino T, Endo F, Ikeda S et al (1996) Three brothers with progressive hepatic dysfunction and severe hepatic steatosis due to a patent ductus venosus. Gastroenterology 110:1964-1968

15. Broere D, van Gemert WG, Kneepkens CM et al (2000) A 6-year-old boy with hyperammonaemia: Partial N-acetylglutamate synthase deficiency or portosystemic encephalopathy? Eur J Pediatr 159:905-907

16. Kamimatsuse A, Onitake $Y$, Kamei N et al (2010) Surgical intervention for patent ductus venosus. Pediatr Surg Int 26:1025-1030

17. Law YM, Mack CL, Sokol RJ (2011) et a1. Cardiopulmonary manifestations of portovenous shunts from congenital absence of the portal vein: pulmonary hypertension and pulmonary vascular dilatation. Pediatr Transplant 15:E162-168

18. Gong Y, Zhu H, Chen J (2015) et a1. Congenital portosystemic shunts with and without gastrointestinal bleeding-case series. PediatrRadiol 45:1964-1971

19. Uchino T, Matsuda I, Endo F (1999) The long-term prognosis of congenital portosystemic venous shunt. J Pediatr 135:254-256

20. Franchi-Abella S, Branchereau S, Lambert V et al (2010) Complications of congenital portosystemic shunts in children: therapeutic options and outcomes. J Pediatr Gastroenterol Nutr 51:322-330

21. Poeppelman RS, Tobias JD (2018) Patent Ductus Venosus and Congenital Heart Disease: A Case Report and Review. Cardiol Res 9:330-333

22. Massin M, Verloes A, Jamblin P (1999) Cardiac anomalies associated with congenital absence of the portal vein. Cardiol Young 9:522-525

\section{Figures}



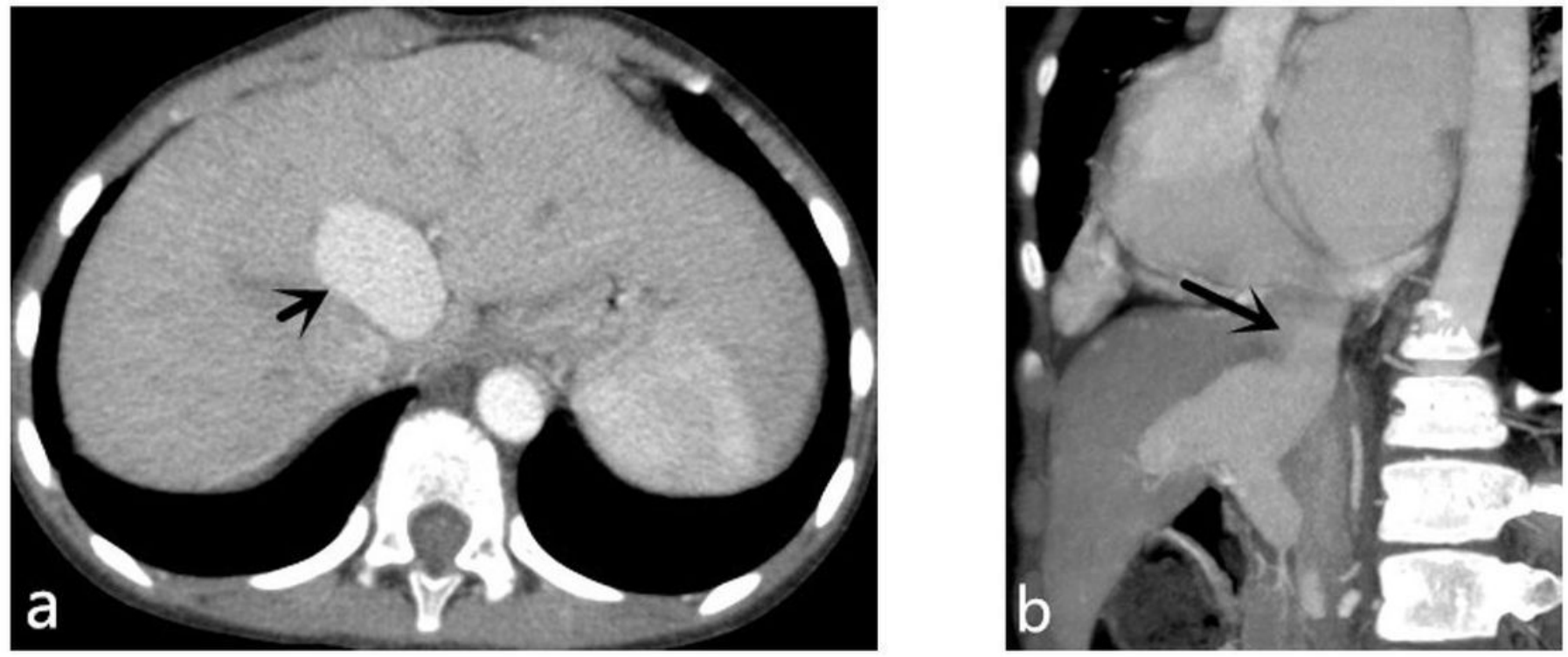

Figure 1

Imaging findings in case 8. Enhanced CT revealed a large PDV (black arrow) between the LPV and IVC.
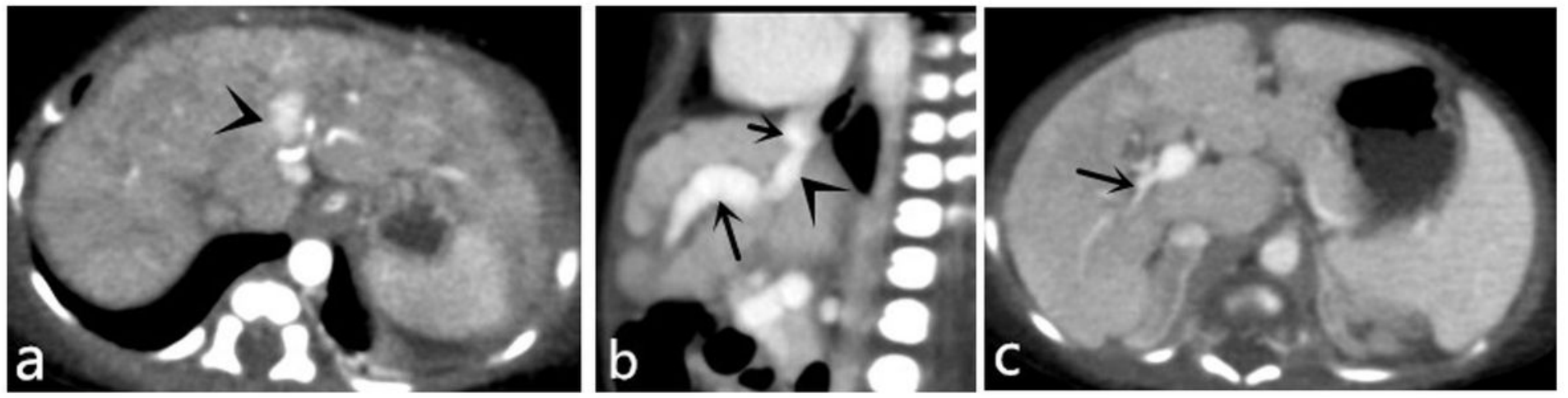

Figure 2

Imaging findings in case 3. Abdominal CT showed a PDV(a, b; arrowhead) between dilated LPV(b, long arrow) and IVC(b; short arrow). Diffuse nodules (a) and atrophic RPV (c; arrow) were detected. 

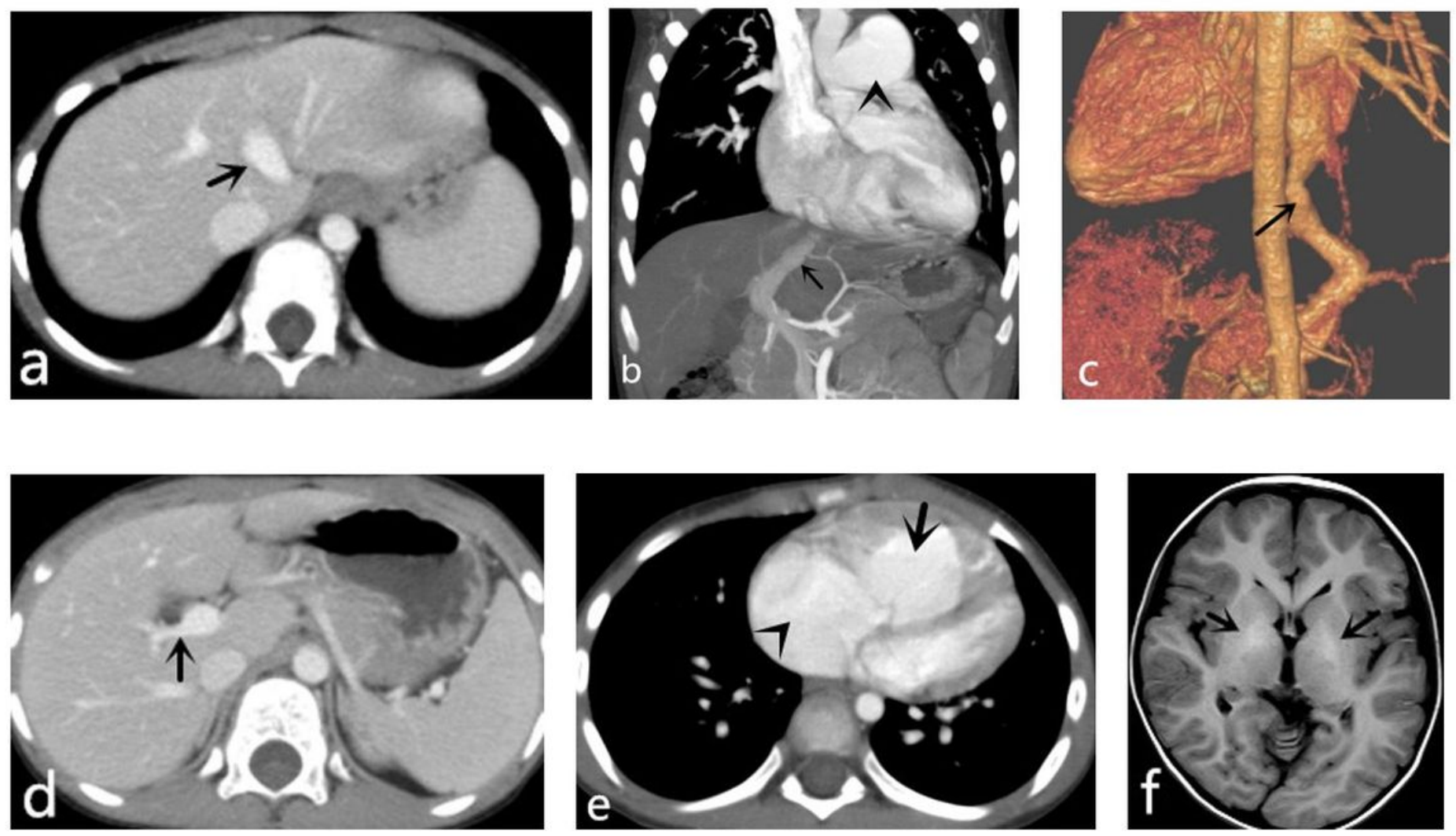

Figure 3

Imaging findings in case 7. PDV (a, b, c; arrow) was shown between LPV and IVC; Atrophic RPV (d, arrow) and significantly dilated pulmonary artery(b; arrowhead) and right heart(e) were detected; Symmetrical hyperintense in bilateral lenticular nucleus(f; arrow) was seen on T1-Weighted Imaging of brain MRI, suggesting hepatic encephalopathy. 